\title{
Über die Fühlhaare von Mimosa und Biophytum.
}

\author{
Von G. Haberlandt.
}

In seiner vor kurzem erschienenen Arbeit „Zur Morphologie und Ökologie der pflanzlichen Behaarung" 1) hat O. Renner gegen die von mir vertretene Auffassung der Borsten auf den Gelenkpolstern von Mimosa pudica und der Haare auf den Blättern von Biophytum sensitivum als Sinnesorgane für mechanische Reize Einwendungen erhoben, die ich hier in Kürze besprechen und zurückweisen möchte.

1. Anatomisches. Nach Renner kommt bei vielen Pflanzen die Aufrichtung der dem Blatt oder dem Stengel ursprünglich angedrückten Haare dadurch zustande, daß das starre und oft tote Haar an seiner Basis durch die angrenzenden Epidermiszellen, die entsprechendes Wachstum zeigen und oft zu einem kleinen Polster werden, einen seitlichen Druck erfährt und so emporgerichtet wird. An diesem Vorgange kann auch das Rindengewebe beteiligt sein ${ }^{2}$ ). Als hierhergehörige Beispiele werden die Haare von Hepatica triloba, Potentillaarten, Fragaria vesca, Agrimonia Éupatorium u. a. genannt. Dieselbe Bedeutung soll auch den Zellpolstern an der Basis der Fühlhaare von Biophytum sensitivum zukommen. Es läge kein Grund vor, sie mit der Reizperzeption in Verbindung zu bringen.

In den von Renner beschriebenen Fällen, die ich zum Teil nachuntersucht habe, bleiben aber die Epidermispolster, welche die Aufrichtung der.Haare bewirken sollen, hinsichtlich ihrer Größe weit hinter den so auffallenden Zellpolstern zurück, die ich an den Basen der Fühlhaare von Biophytum sensitivum und proliferum gefunden habe. Zur Aufrichtung angedrückter Haare genügen, wie auch die Abbildungen Renners lehren, schon wenig vorragende Polster, bei Hepatica triloba nach Renners Abbildung (Fig. 10b, pag. 141) eine einzige Epidermiszelle. Dabei kann der Aufrichtungswinkel des Haares weit mehr als $90^{\circ}$ betragen. Bei Biophytum dagegen beträgt dieser Winkel bei den auf der Blattspindel stehenden Haare nur $60-80^{\circ}$, bei den auf den

1) Flora 1908, Bd. 99, pag. $127 \mathrm{ff}$.

2) Die Frage, ob die basalen Polsterbildungen vieler Haare tatsächlich, wie Renner will, in erster Linie oder ausschließlich zur Aufrichtung der Haare dienen, lasse ich hier unberührt. Die Möglichkeit, daß es sich um eine Aussteifung der Haarbasis handeln könnte, hat Renner nicht in Betracht gezogen, obgleich er selbst in den schräg abstehenden steifen Haaren an Stengeln und Blattstielen eine Einrichtung gegen das Aufkriechen kleinerer Tiere erblickt. 
Blättchenspreiten vorkommenden noch weniger. Und doch diese auffallenden, stark emporragenden Gewebepolster auf der Konkavseite der Haarbasis mit ihren charakteristischen Zellteilungen! Zur Aufrichtung der Haare würden, wie die nicht reizbaren Haare anderer Pflanzen lehren, weit schwächer ausgebildete Polster, mit weniger Zellen, vollkommen ausreichen. Die Polster müssen demnach bei Biophytum noch eine andere Aufgabe haben.

Außer den „Fühlhaaren" kommen bei Biophytum sensitivum und proliferum am Stengel und an der Infloreszenzachse, sowie an der Blattspindel noch kleinere, ziemlich dickwandige Haare vor ${ }^{1}$ ), die gleichfalls mehr oder minder schräg aufgerichtet sind, oft ebenso stark und noch stärker als die Fühlhaare, und die dennoch an ihrer Basis keine Spur eines Gewebepolsters zeigen. Die Aufrichtung dieser Haare erfolgt also durch Wachstumsvorgänge, die nicht zur Bildung eines Polsters führen. Es ist nicht einzusehen, warum dies nicht auch bei den größeren Haaren möglich sein sollte. Auch diese Tatsache lehrt also, daß die starken Gewebepolster der Fühlhaare zum mindesten nicht ausschließlich der Aufrichtung der Haare dienen.

Übrigens halte ich es für ganz gut möglich, ja wahrscheinlich, daß die phylogenetische Ausbildung der Fühlhaare von Biophytum von Haarformen ihren Ausgang genommen hat, die an ihrer Basis auf der Konkavsęite die von Renner beschriebenen Zellpolster besessen haben. Diese Polster sind ihrer Lage nach besonders starken Deformationen ausgesetzt, wenn von einem aufkriechenden Insekte der steife Haarkörper als Stimulator niedergedrückt oder zurückgebogen wird. Eine Steigerung oder Lokalisierung der Empfindlichkeit war also an diesen Stellen ganz am Platze. Hand in Hand ging damit eine Vermehrung der sensiblen Zellen des Polsters.

An den Gelenkpolstern von Mimosa pudica habe ich drei Typen von Fühlborsten beobachtet ${ }^{2}$ ): 1. die Borste besteht nur aus einem Bündel mechanischer Zellen und kann demnach nur als Stimulator wirken; 2. das mechanische Zellbündel sitzt auf einem zartwandigen, parenchymatischen Postament; 3. in dem Winkel zwischen Borste und Gelenkoberfläche befindet sich ähnlich wie bei Biophytum ein zartwandiges Gewebepolster, das an der Basis eine Gelenkfalte aufweist. Dieser Typus ist der vollkommenste. Während ich ihn bei unseren Grazer Gewächshauspflanzen mindestens ebenso häufig wie den zweiten

1) G. Haberlandt, Sinnesorgane im Pflanzenreich, II. Aufl., pag. 111, 112.

2) Sinnesorgane, II. Aufl., pag. 105, 106. 
Typus beobachtet habe, ist er Renner mit einer einzigen zweifelhaften Ausnahme nie zu Gesicht gekommen. Schon in der ersten Auflage meines Buches (pag. 84) habe ich darauf hingewiesen, daß unsere Gewächshauspflanzen hinsichtlich des Vorkommens der verschiedenen Borstentypen ein ziemlich schwankendes, vielleicht abnormes Verhalten zeigen. Nur so kann ich mir den negativen Befund Renners bezüglich des dritten Borstentypus erklären.

2. Physiologisches. Biophytum sensitivum ist eine sehr heikle Pflanze, die in unseren Gewächshäusern nicht gut gedeiht. Trotzdem ist es mir wiederholt gelungen, die Reizbewegung der Fiederblättchen auszulösen, wenn ich die auf der Oberseite der Blattspindel und der Fiederblättchen befindlichen „Fühlhaare“ mit einer Nadel streifend berührte und einbog. Renner hat diesen Versuch stets erfolglos ausgeführt, während ein Schlag auf die Spindel Erfolg hatte. Ein geeigneteres Versuchsobjekt als das bei uns meist träge reagierende Biophytum sensitivum ist B. proliferum, das ebenso gebaute Fühlhaare aufweist ${ }^{1}$ ) wie ersteres, und im kleinen Warmhause des Grazer botanischen Gartens vortrefflich gedeiht, ja geradezu als Unkraut auftritt. Versuche, die ich im September l. J. mit dieser Art angestellt habe, haben weit befriedigendere Ergebnisse geliefert als die mit B. sensitivum. Die abgeschnittenen Endrosetten wurden mit ihren Stielen in durchlöcherte Korkscheiben gesteckt, die einer am Grund einer größeren Glasschale befestigten Hartgummibrücke aufgekittet waren. Die Schale wurde bis über die Korkscheibe mit Wasser gefüllt. Am nächstfolgenden Tage, nachdem sich die Versuchsobjekte erholt und die Fiederblättchen schön ausgebreitet hatten, wurde das Wasser in der Glasschale langsam angewärmt, bis es eine Temperatur von ca. $30^{\circ} \mathrm{C}$ angenommen hatte. Nun wurden unter einer B rück eschen Lupe einzelne Fühlhaare, die in der Nähe eines Blättchengelenkes; oder auf einem solchen standen, mit einer feinen Nadelspitze vorsichtig niedergedrückt oder zurückgebogen. In den meisten Fällen genügte díe Verbiegung ein es Haares, um die Reizbewegung des Blättchens auszulösen, wobei allerdings nur eine Senkung des Blättchens um ca. $20-40^{\circ}$ eintrat. Wiederholt stellte sich die Bewegung auch dann ein, wenn das Haar in niedergedrückter oder zurückgebogener Stellung erhalten wurde. Ein rasches Zurückschnellen des Haares wurde überhaupt vermieden. Die Funktion der Haare als Sinnesorgane ist demnach wohl nicht zu bezweifeln.

1) Vgl. Sinnesorgane, II. Aufl., pag. 116 ff. 
$\mathrm{Da}$ bei Mimosa pudica die Verbiegung der Borsten auf der sensiblen Unterseite der primären Gelenkpolster die Reizbewegung auslöst, hat auch Renner beobachtet, allerdings nur bei Pflanzen, die sich auch sonst als sehr empfindlich erwiesen. Demgegenüber muß ich nochmals betonen, daß auch bei wenig empfindlichen, ja selbst kränklichen Pflanzen der Versuch sehr gut gelingt. Auch heuer habe ich am 17. Sept. bei einer Temperatur von $22^{\circ} \mathrm{C}$ an Freilandpflanzen die Reizbewegung auf die in Rede stehende Art prompt auslösen können. An Gewächshausexemplaren gelang zur selben Zeit der Versuch auch noch mit älteren Blättern, deren Fiederblättchen an den Spitzen bereits vergilbt waren.

Die Einwände, die Renner gegen meine Auffassung der in Rede stehenden Haarbildungen als Fühlhaare und Fühlborsten vorbringt, sind demnach sowohl in anatomischer wie in physiologischer Hinsicht unberechtigt. Ich habe keine Veranlassung, an meinen früheren Darlegungen hierüber etwas zu ändern. 